examined on six occasions before being considered negative and allowed to return to duty. Six positives were obtained among these men. All other cook-house personnel who denied a history of diarrhoea had three specimens of faeces examined, but were allowed to continue their work in the cook-house without interruption.

The exclusion of suspicious cooks from the cook-house was completed on Aug. 11; the last fresh case of enteritis occurred on Aug. 13, and I considered that by Aug. 20 the regiment could be considered free from infection. Owing, however, to the expected activities of this regiment, Higher Authority considered that the risk of another outbreak should be excluded with certainty, and eventually every man in the regiment who had not previously been examined, because he gave no history of diarrhoea, had two specimens of faeces tested. It is of interest that not a single further positive result was obtained.

\section{The Carrier}

At least one Sonne-positive case was found among the personnel in each cook-house, but only one man whose history of diarrhoea was outside the limits of the incubation period. This was Gunner P., who gave the following history.

While stationed in Scotland in Aug., 1942, he had been admitted to a camp reception station with acute enteritis, pyrexia, colic, and frequent stools containing blood and mucus. He was in bed for about 7 days, but no investigation was carried out. In Nov., 1942 he was posted to this regiment, and in Feb., 1943, was employed in the sergeants' quarters. His duties included providing the sergeants with cups of tea, bread-and-butter, etc., at various times. At this period there was a mild outbreak of enteritis in the regimentsome 80 cases in all, of which the majority were sergeants. No investigation was carried out, however, and the outbreak apparently died down. For some months he was then employed on the guns, but on July 7 he was detailed for duty as orderly in one of the regimental cook-houses at the practice camp. His job was mainly cutting bread-and-butter. The first cases occurred about July 20 , and were among the battery personnel served from this particular cook-house.

It is certain that in the course of his duties Gunner P. visited the other regimental cook-houses to lend or borrow on numerous occasions, and thus infection would be conveyed to food and personnel in them, with consequent spread of the epidemic to the remaining two batteries. It was equally certain, for administrative and other reasons, that he did not so visit the permanent staff cookhouse. It has been noted that no cases occurred among the personnel served from there. This man had had no symptoms since his moderately severe attack 12 months previously, but his stool showed a heavy infection of $B$. dysenteriae Sonne.

\section{Comments}

It is evident that Gunner P. was the carrier in this outbreak, since he was the only Sonne-positive found who had not had any symptoms within the limits of the epidemic. He had had, in fact, no symptoms whatsoever since his enteritis of 12 months previously, while his history was exceedingly suggestive and his work as a cutter of bread-and-butter was ideal for the spread of the organisms. There can be no doubt that here was an outbreak of Sonne dysentery spread by food-by far the commonest vehicle-infected by a chronic symptomless carrier of a year's duration.

I consider that symptomless carriers are responsible for many of the recently frequent outbreaks of Sonne dysentery in this country. However, I would suggest that they are only symptomless in that they have had no symptoms for, maybe, many months. but that with careful questioning a history of diarrhoea, or perhaps just "looseness of the bowels," at some time in the past will be obtained. This opinion is borne out by the fact that in the outbreak described above not a single positive stool was obtained from the remaining two-thirds of the regiment who were subsequently examined but who had given no history of illness previously. In other words, no positive case was found that did not give a history of diarrhoea at some time.

It is impossible to over-emphasize the importance of careful questioning of all persons connected with food preparation in any outbreak of dysentery : this, followed by the segregation of all those with a history of diarrhoea, bowever slight, will almost always put an end to the outbreak. Gardener (1929), when discussing asylum dysentery, stated that carriers are the main source of infection; while HobBs and Allison (1942) have also recently stressed the importance of carriers and ambulant cases in the spread of the disease. However, although the carrier state is generally admitted, only rarely has a single definite carrier been found in an epidemic of any size. Yet it is essential to isolate such a carrier before one can be satisfied that any such epidemic has been finally brought to an end. Milk, water, food, have all been involved in some or other outbreak, but often the human factor is neglected. The vehicle-and cold uncooked foods should always be primarily suspect-is a link in the chain which will, if carefully followed, bring the investigator to the human focus of the infection.

\section{Summary}

An outbreak of Sonne dysentery in a virtually closed community is described.

It was discovered that a chronic symptomless carrier had spread the infection by food during his duties in the cook-house.

The removal of all infected cooks from the cook-house immediately stopped the outbreak.

The opinion is put forward that the so-called symptomless carrier of Sonne dysentery is common, but that a history of diarrhoea at some time in the past can usually be obtained.

I wish to thank Capt. C. E. Perry and Lieut. Madison, R.A.M.C., for their help at the scene of the epidemic; Dr. R. M. Fry of the E.P.H. Laboratory Service for his reports on numerous specimens; and the D.D.M.S., Western Command, for his permission to publish this account.

Bloch, E. (1938). British Medical Journal, 1, 836

Buckle, D. (1938). Lancet, 2, 913.

Cruickshank, R., and Swyer, R. (1940). Ibid., 2, 803

Gardener, A. D. (1929). System of Bacteriology, 4, 244.

Graham, J. R. (1942). Lancet, 2, 553

Green, C. A., and Macleod, M. C. (1943). British Medical Journal, 2, 259.

Hobbs, B. C., and Allison, V. D. (1942). E.P.H.L.S. Bulletin, July.

Irvine, E. D. (1942). Med. Officer, 67, 53

Laws, J. J. (1936). Lancet, 1, 192.

. Med. Officer, 56, 203.

Thornton, L. H. D and Darmady, E. M. (1938). Lancet, 1, 25.

Wiseman, W. R. (1927). Ibid., 1, 817.

\section{AN ANALYSIS OF COLLES'S FRACTURE} BY

S. C. ROGERS, B.S., M.R.C.S.

Late Casualty House-surgeon, St. Mary's Hospital, Paddington

“No two Colles's fractures are alike."-SPEED (1935).

At first when examining and reducing Colles's fractures this aphorism seemed too true. Later, recurring types were noted, and it was decided to review the radiographs of a series of fractures around the lower end of the radius seen at this hospital between Jan., 1942, and Oct., 1943.

Descriptions of the varieties of comminution of the lower radial fragment in Colles's fracture are absent from surgical textbooks and vague in works on orthopaedics. Comminuted forms are recognized by Platt (1932) and others, and a vertical posterior marginal crack involving the wrist-joint is described by Clayton and Edwards (1929).

Very divergent views on the cause of poor end-resulis are given. Platt (1935) and Taylor and Parsons (1938) stress the bad prognosis of coincident fractures of the base of the ulnar styloid and injuries to the triangular fibrocartilage, but do not think involvement of the ulnar notch of the radius important. Grasby and Trick (1929) find that imperfect reduction leads to osteo-arthritis of the inferior radio-ulnar joint. Clayton and Edwards (1929) and Bankart (1929) stress the reduction of backward rotation and Mayer (1939) of supination. Finally Lewis (1934) blames lack of co-operation by the patient in active exercises. Thus, given satisfactory reduction and its maintenance'and the adequate supervision of active exercises, injuries to the base of the ulnar styloid and the triangular fibrocartilage appear to lead to most trouble. In this analysis Colles's fractures are divided into types with different degrees af damage and mechanisms. A short anatomical account of the radio-ulnar joint will enable the discussion to be followed more readily.

\section{Anatomy}

The ulnar collateral ligament of the wrist is attached to the tip of the ulnar styloid process. The apex of the triangular 
fibrocartilage of the inferior radio-ulnar joint is attached to the floor and walls of the small pit at the radial side of the base of the ulnar styloid. This fibrocartilage spreads out to a linear-insertion along the edge of the ulnar notch of the radius, and its margins are prolonged into the loose anterior and posterior capsule of the radio-ulnar joint. Thus a fracture across the base of the ulnar styloid or the splitting off of the postero-medial corner of the lower end of the radius enables the main portion of the radius to displace the fibrocartilage without seriously injuring it.

\section{Analysis and Discussion}

In all, 328 fractures around the lower end of the radius have been analysed; 13 epiphysial injuries and the rare greenstick Colles's fracture have been included. The common greenstick fracture of the radius, fractures of the lower shaft of both forearm bones, and carpal fractures have been excluded.

The 219 Colles-type fractures fall into five groups with surprising clarity:

(A) 59 simple Colles's fractures-i.e., fractures not involving the radio-carpal articular surface, but often with fragments of the posterior cortex flaked off, usually including Lister's tubercle (see Fig. 1).

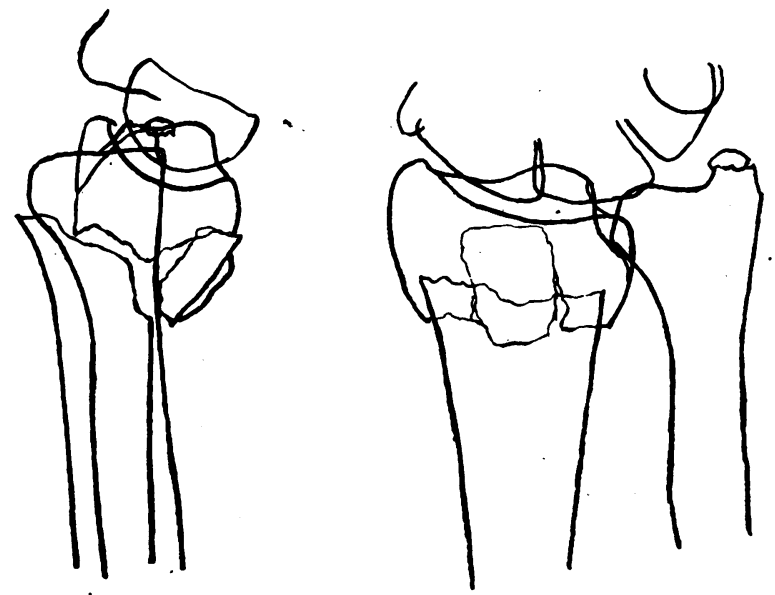

FIG. 1.-Simple Colles's fracture with severe displacement and shortening. Probable rupture of triangular fibrocartilage. Note tubercle of Lister in flake off posterior cortex. (Groüp.A.)

(B) 108 fractures with an oblique postero-medial fragment containing part of the ulnar notch of the radius and so the attachment of the triangular fibrocartilage, and involving both radio-carpal and radio-ulnar joints (see Fig. 2).
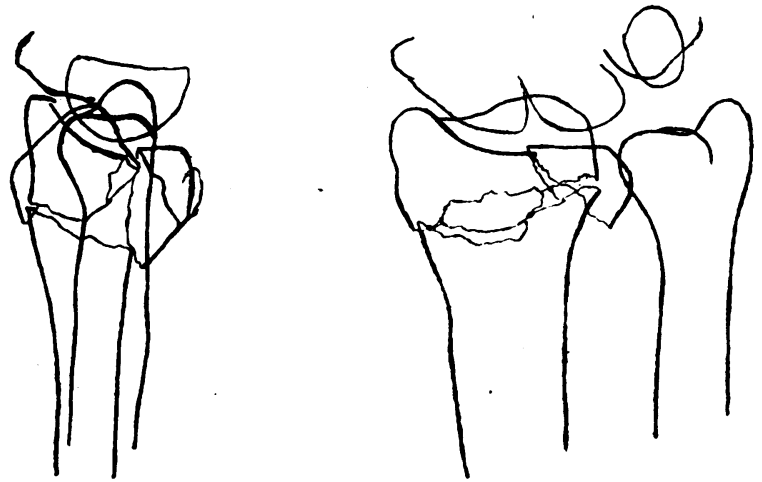

Fig. 2.-Colles's fracture with small postero-medial fragment. Medial displacement and shortening of this fragment suggest posterior subluxation of intact fibrocartilage. (Group B.)

(C) 39 " comminuted Colles's fractures" in which a fracture of the base of the radial styloid passes from the centre of the radiocarpal articular surface obliquely to the lateral surface of the radius, in association with the above postero-medial fragment (see Fig. 3).

(D) 11 fractures with a vertical fracture of the radial styloid, with or without a postero-medial fragment.

(E) 2 fractures with a transverse fracture of the base of the radial styloid passing from the articular surface directly laterally, without a postero-medial fragment.
The other 19 cases include 8 fractures of the styloids ( 2 ulnar and 6 radial), 5 marginal fractures of the radius, and 6 Smith's fractures.
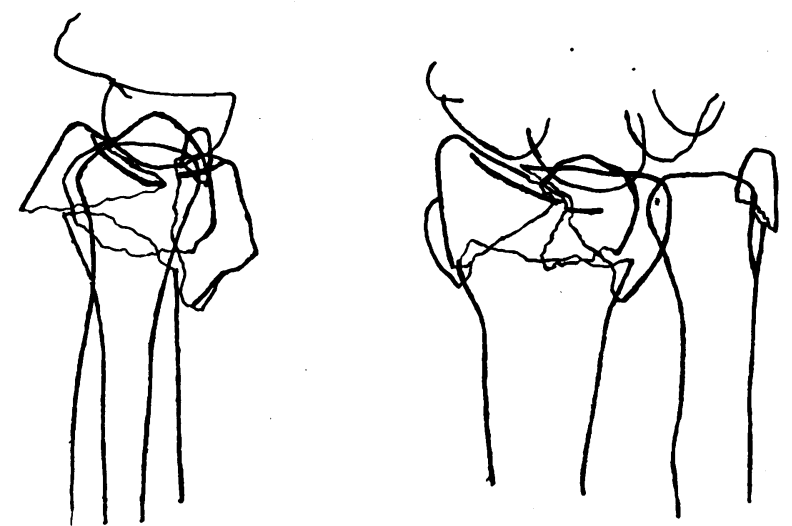

FIG. 3-Comminuted Colles's fracture with oblique fracture of radial styloid and large postero-medial fragment. Note backward displacement of whole ulnar styloid and fibrocartilage. (Group C.)

A detailed analysis of the Colles's fractures according to the presence of shortening of the postero-medial corner of the radius, the type of fracture of the ulnar styloid, and the severity of the displacement of the main fragments, was made, and on its results the following remarks are based.

Clayton and Edwards's (1929) observation that it is the long narrow type of ulnar styloid that breaks at its tip, whereas the short broad type is less often fractured, has been confirmed.

In general, basal fractures of the ulnar styloid are rare when displacement is minimal and frequent when severe, especially if shortening at the radio-ulnar joint is present. In fact, there are only 16 cases out of 219 in which the presence of shortening at the radio-ulnar joint without a basal fracture of the ulnar styloid suggests a rupture of the triangular fibrocartilage. A postero-medial fragment is present in all but one of these 16 cases, and in many the extreme medial displacement of this fragment suggests a posterior subluxation of the intact ligament rather than an actual rupture. This explains the rarity of instability of the radio-ulnar joint as a late sequela (Hyman and Martin, 1940), and the usual excellent return of pronation and supination.

Group B contains most of the more severe fractures and shows many basal fractures of the ulnar styloid. The posteromedial fragment varies in size from an apparent avulsion of the insertion of the radio-ulnar fibrocartilage to a fragment like the isolated posterior marginal fracture, and its vertical direction suggests that it is a compression fracture. In group $\mathrm{C}$ the bending force that produces the Colles's fracture is combined with a compression force directed backwards and laterally, splitting off the posterior and lateral portions of the articular surface and leaving an anterior marginal fragment which is sometimes rotated slightly forward (see Fig. 3 ). This compression and lateral displacement mechanism accounts for the frequency of shortening and of basal fractures of the ulnar styloid. Group.D is small, and represents a compression fracture in which the force is directed almost vertically down the shaft of the radius. Group E combines the Colles with a transverse shearing fracture of the radial styloid-one of the chauffeurs' fractures.

All these types of secondary fracture may occur isolated, and similar comminutions may be seen in Smith's fractures.

\section{Reduction}

A general method of reduction is described and discussed below. The strength of the manipulations should be varied with the exact displacement seen in antero-posterior and lateral radiographs.

Nitrous oxide anaesthesia is satisfactory provided a dry slab is prepared before reduction, that during plastering the slab is rendered almost dry, and that hot water is used. (This accelerates setting of the plaster.) 
1. Strong steady traction on the hand in slight radial deviation obtains disimpaction, overcomes shortening at the radio-ulnar joint, and, if strong enough, secures anterior cortex-to-cortex apposition

2. Strong traction in 30 degrees palmar flexion with direct pressure, by the chin if necessary, over the lower fragments corrects backward rotation without further trauma to the joint capsule.

3. Traction in ulnar deviation and pronation corrects radial deviation and supination.

4. Direct antero-posterior and lateral compression moulds the fragments.

This method is similar to many others, but I would stress that, unless disimpaction is carried out by strong traction in radial deviation, shortening at the radio-ulnar joint and posterior subluxation of the triangular fibrocartilage may persist.

The method of Sir Robert Jones (or, rather, of Hugh Owen Thomas-see Parker. 1929) is satisfactory if there is no shortening or gross comminution, but a generally applicable method is preferred.

\section{Immobilization and After-treatment}

Reduction is confirmed and its stability tested. The arm is held in moderate traction in the mid-pronated position with considerable ulnar deviation and no palmar flexion. The thumb is opposed, abducted, and flexed to meet the flexed index finger. A $\frac{7}{8}$-circle plaster back slab is applied gripping the anterior surfaces of radius and ulna and the dorsal surface of the first metacarpal, and taking a long grip of the upper end of the ulna. This position helps to maintain the full length of the radius. The slab is secured with a dry cotton bandage. No moulding is performed if the fracture is stable, but if unstable -as, rarely, it is-careful moulding to the anterior radial concavity is essential.

Reduction is checked radiographically, and graduated and vigorous active exercises to fingers, elbow, and shoulder are started immediately under supervision. A high sling is worn for three or four days. The plaster is removed after five weeks and the exercises are intensified. The patient usually returns to light clerical work after one week (in plaster), to light manual work after seven weeks, and to heavy work after about nine weeks. He is discharged when his range of movement is approaching that of the normal side and he has been doing his usual work without complaint for at least a week.

It is hoped to discuss in detail the results of a smaller series later.

\section{Summary}

238 fractures about the lower end of the radius have been analysed and shown to fall into certain definite groups. Their mechanisms have been discussed and their treatment outlined.

I am much indebted to Mr. V. H. Ellis, honorary orthopaedic surgeon to St. Mary`s Hospital, for his encouragement and helpfu criticism; and to my fellow casualty house-surgeons for their co-operation and stimulation.

\section{REFERENCES}

Bankart, A. S. B. (1929). British Medical Journal, 1, 491.

Clayton, E. B., and Edwards, H. (1929). Ibid., 1, 61

Colles, A. (1814). Edinb. med. surg. J 10, 182.

Grasby, E. D., and Trick, S. R. (1929) British Medical Journal 1, 391.

Hyman, G., and Martin, F. R. R. (1940). Brit. J. Surg., 27, 48i.

Lewis, K. M. (1934). Ann. Surg., 99, 510.

Mayer, J. H. (1939). British Medical Journal, 1, 1197.

Parker, R. (1929). Ibid., 1, 705.

Platt, H. (1932). Ibid., 2, 288.

- (1935). Surg. Gynec. Obstet., 60,542.

Speed, K. (1935). Fractures and Dislocations, H. Kimpton, London.

Taylor, G. W., and Parsons, C. L. (1938). Surg. Gynec. Obstet., 67, 249.

A message from Washington announces the appointment of Dr. Wilbur A. Sawyer, of New York, as Director of Health of the United Nations Relief and Rehabilitation Administration. He will be assigned to Washington and will be in charge of the Health Division of UNRRA and be responsible for planning and directing health and medical activities. His duties will require frequent visits abroad to the regional offices and field work. Dr. Sawyer has had long experience in international health activities through his connexion with the Rockefeller Foundation's International Health Division, of which he has been director for nine years. During his service with the Rockefeller Foundation he directed a hookworm campaign in Australia, made investigations of yellow fever in West Africa, carried on research in New York that revealed a method of vaccinating against yellow fever, and negotiated and. planned co-operative projects with the health authorities of many countries of both hemispheres.

\section{AN OUTBREAK OF PUERPERAL SEPSIS DUE TO A SINGLE TYPE OF HAEMOLYTIC STREPTOCOCCUS} ITS INVESTIGATION AND REMEDY

\author{
BY \\ MEAVE KENNY, M.R.C.O.G. \\ AND \\ MARY BARBER, M.D.
}

(From the Departments of Obstetrics and Pathology of the British Postgraduate Medical School, Hammersmith Hospital)

From 1935, in the obstetric unit of the British Postgraduate Medical School, a carefully conceived and operated routine has obtained good results in the prevention of epidemics of puerperal sepsis. Among 12,283 deliveries, only 19 isolated cases of haemolytic streptococcal infection of the genital tract have occurred, and none of these could be traced to respiratory tract infection of attendants. In 1938 and 1939 not one occurred. One woman has died of puerperal sepsis since the founding of the unit-a non-haemolytic streptococcal peritonitis developing after Caesarean section for placenta praevia in an emergency case which had been examined vaginally by outside attendants; and one has died of lobar pneumonia complicating localized uterine non-haemolytic streptococcal infection.

\section{Preventive Routine}

Booked cases without septic foci and with intact membranes are admitted in labour to a "clean" suite (D 6), and after delivery are drafted to "clean" lying-in wards (D 3 and D 5). These wards are made up of several 4-bed units. Unbooked cases without septic foci and booked cases with ruptured membranes are delivered and spend the lying-in period in a "suspect" suite (D 4). Vaginal swabs of all such patients are sent for routine bacteriological investigation, and pyrexial cases are removed from this and the "clean" wards to the isolation block. All cases found to have-respiratory tract or other infection are admitted, delivered, and nursed in the isolation block of 10 single-bed rooms and attached labour theatre. These cases, too, have bacteriological investigation of the genital and other tracts performed as a routine measure, whether they are febrile or not.

Each suite has a separate nursing staff; the isolation block has its own house-surgeon, who does not enter the other suites. The visiting and resident obstetricians change their overalls before entering each ward and wear masks covering nose and mouth when in the isolation block, when examining women in labour, and in the delivery theatres. All students and members of the staff 'submit to a bacteriological investigation of the respiratory tract before joining the unit and on return from holiday. Respiratory tract or other infections bar entrance to the unit pending a bacteriological report on the nature of the infection.

Each patient when admitted in labour has a shower-bath and, after shaving, has the vulva and surrounds painted fourhourly with dettol $30 \%$ cream until delivery has taken place. In addition, women in the isolation block with upper respiratory tract infections have their hands anointed with the cream. Dettol cream is also used as a lubricant for pelvic examinations and instrumental deliveries; dettol $10 \%$ lotion is employed for swabbing the vulva in the early puerperium.

- The following is a report of a recent epidemic of haemolytic streptococcal puerperal sepsis that overleaped these precautions, its investigation and remedy.

\section{Case Records}

Case 1.-On Jan. 10, 1944, Mrs. E., primipara, was admitted in the first stage of labour to the clean suite D 6 . She was delivered $5 \frac{1}{2}$ hours later by Sister M. and a student and sent on to lying-in ward D 5. On the 12th her temperature rose to $103^{\circ} \mathrm{F}$. She was at once transferred to the isolation block. Bacteriological investigation of her lochia showing haemolytic streptococci, she was removed to the North-Western Fever Hospital, and recovered under sulphonamide therapy, as did all the other women involved in the outbreak. 